\title{
Antibacterial Activity of Aloe vera Gel against Multidrug Resistant Staphylococcus aureus and Pseudomonas aeruginosa
}

\author{
*1'Usman, A., ${ }^{2}$ Hussaini, I.M., ${ }^{1}$ Hamza, M.M., ${ }^{1}$ Sanusi, S.B. and ${ }^{1}$ Idris, H. \\ ${ }^{1}$ Department of Microbiology, Faculty of Science, Kaduna State University, Kaduna. \\ ${ }^{2}$ Department of Microbiology, Faculty of Life Sciences, Ahmadu Bello University, Zaria. \\ * Corresponding author: Usmanaisha1104@gmail.com; +2348036835348.
}

\begin{abstract}
Staphylococcus aureus and Pseudomonas aeruginosa have been implicated as important nosocomial pathogens causing severe infections especially in hospitalized patients. The aim of the study was to assess the antibacterial activity of Aloe vera gel against multidrug resistant $S$. aureus and P. aeruginosa isolated from wound. Clinical isolates of S. aureus and P. aeruginosa from wound infection were collected from Microbiology laboratory of Barau Dikko Teaching Hospital (BDTH), Kaduna and re-confirmed using standard microbiological procedure. Antibiotic susceptibility pattern of the isolates was determined using Kirby Bauer disk diffusion method. Aloe vera gel was obtained fresh matured leaves of Aloe vera plant and was screened for the presence of phytochemical constituents. Antibacterial activity of the Aloe vera gel against Multidrug Resistant (MDR) Staphylococcus aureus and Pseudomonas aeruginosa isolates was determined by agar well diffusion technique. The result revealed that all the two isolates were resistant to more than three classes of antibiotics. The Staphylococcus aureus isolate was resistant to fluoroquinolone (ciprofloxacin), aminoglycoside (gentamicin), cephalosporin (cefaroline), folate pathway antagonist (trimethoprim-sulfamethoxazole), penicillin(cefoxitin) and macrolide (erythromycin) while the Pseudomonas aeruginosa isolate was resistant to Blactam (ticarcillin-clavulanate), fluoroquinolone (ciprofloxacin and norfloxacin), aminoglycoside (gentamicin) and cephalosporin (ceftazidime)hence regarded as MDR isolates. Phytochemical screening of the gel revealed the presence of saponins, flavonoids, terpenoids and alkaloids. The Aloe vera gel was found to have antibacterial activity against the test isolates with MIC and MBC values of $25 \mu \mathrm{g} / \mathrm{mL}$ and $50 \mu \mathrm{g} / \mathrm{mL}$ against MDR S. aureus $50 \mu \mathrm{g} / \mathrm{mL}$ and $100 \mu \mathrm{g} / \mathrm{mL}$ against MDR P. aeruginosa respectively. The study identified that Aloe vera gel possesses antibacterial activity against MDR S. aureus and $P$. aeruginosa isolated from wound infection.
\end{abstract}

Keywords: Aloe vera gel, Staphylococcus aureus, Pseudomonas aeruginosa, antibacterial, MDR

\section{INTRODUCTION}

The development of resistance against convectional antibiotics has led to researchers looking for alternative medicine in many countries today (Ingrida et al., 2012). Approximately $20 \%$ of the world's plants have been pharmacologically tested against majority of pathogenic microorganisms (Adnan et al., 2015). This has led to introduction of new antibiotics into the drug market (Radha and Laxmipriya, 2015).

One of the plants that have gained a lot of popularity in medicine is Aloe barbadensis Miller (Aloe vera) belonging to the family Liliaceae (Seyyed et al., 2015). The plant is succulent with a whorl of elongated, pointed leaves with over 360 known species. Aloe vera has been shown to have anti-inflammatory activity, immune stimulatory, antioxidant, immune modulating and cell growth stimulating activity (Yebpella et al., 2011). In addition, extracts from Aloe vera have reported to possess antimicrobial, antiviral and antifungal properties (Jothi et al., 2014).

Aloe vera has been used widely in the treatment of various skin conditions such as cuts, burns and eczema. It is reported that sap from Aloe vera eases pain and reduces inflammation. Hence, the current wide use of the plant in skin care, cosmetics and as nutraceuticals (Arunkumar and Muthuselvam, 2009).

Staphylococcus aureus is one of the important hospital and community acquired pathogen. It is responsible for causing a broad spectrum of diseases ranging from mild superficial skin and soft tissue infections to life threatening infections such as infective endocarditis, septicaemia, deep-seated abscess, pneumonia and toxic-shock syndrome (Onemuand Ophori, 2013). S. aureus has been naturally susceptible to most of the antibiotics developed so far (Chambers and DeLeo, 2009). 
UJMR, Volume 5 Number 2, December, 2020, pp 1 - $80 \quad$ ISSN: 2616 - 0668

However, it has been developing increased resistance to antimicrobial agents (Foster, 2017). It is of greatest concern because of its intrinsic virulence and its ability to adapt to different antibiotics (Lowy, 2013). The two most remarkable antibiotic resistance achieved by $S$. aureus is methicillin (MRSA) and vancomycin resistance (VRSA and VISA). Methicillin resistance was achieved by interspecies transfer of mecA gene from an ancestral Staphylococcus species to S. aureus. Vancomycin resistance was achieved by gene mutations (VISA) and horizontal genes transfer (van A-gene) (Hiramatsu et al., 2014).

Pseudomonas aeruginosa is increasingly recognized as important nosocomial pathogens causing severe infections especially in hospitalized patients in burn wards (Japoni et al., 2014). This opportunistic and highly resistant pathogen is responsible for a variety of nosocomial infections, including wound and urinary tract infections, bacteremia, endocarditis, and in some conditions death. $P$. aeruginosa infections in immunocompromised, debilitated, cystic fibrosis, and burn patients are associated with increased rates of mortality and morbidity (Japoni et al., 2014).

Development of antibiotic resistance mechanisms eitherintrinsic or acquired has promoted the rapid developmentof multiple resistances among $P$. aeruginosa isolates in the clinical settings. The rapid increase of drug resistance inclinical isolates of $P$. aeruginosa is a growing concern among hospitalized patients. The widespread multidrug-resistant (MDR) $P$. aeruginosa strains not only lead to increased economicburden, but also can directly threaten the life of the patient (Goudarzi et al., 2015). The aim ofthis study was to evaluate the antibacterial activity $f$ Aloe vera gel against MDR S. aureus and $P$. aeruginosa isolated from wound infections.

\section{MATERIALS AND METHODS}

Sample Collection and processing

Matured and fresh leaves of Aloe vera were collected from Faculty of Arts, Kaduna State University, Kaduna in a clean container. Leaves were washed thoroughly with a sterile water to remove dirt and their thick epidermidis was then dissected longitudinally into pieces. The colourless parenchymatous tissue (Aloe vera gel) was collected in a sterile container. Two hundred grams $(200 \mathrm{~g})$ of the gel was mixed in one liter $(1 \mathrm{~L})$ of $2.0 \%$ Dimethyl Sulfoxide (DMSO) to make $200 \mu \mathrm{g} / \mathrm{mL}$ stock solution and kept at $4^{\circ} \mathrm{C}$ for further analysis. This stock solution was serially diluted to achieve $100 \mu \mathrm{g} / \mathrm{mL}, 50 \mu \mathrm{g} / \mathrm{mL}$, $25 \mu \mathrm{g} / \mathrm{mL}$ and $12.5 \mu \mathrm{g} / \mathrm{mL}$
The Aloe vera gel was screenedfor the presence of the phytochemicals: alkaloids, saponin, tannins, terpenoids, steroids, flavonoids, cardiac glycosides and phlobatannins as follows:

\section{i. Test for alkaloids}

This test was carried out by adding $1.5 \mathrm{~mL}$ of $1 \% \mathrm{HCl}$ to $2 \mathrm{~mL}$ of the gel. The solution was then heated in a water bath before adding 6 drops of Wagner'sreagent. Formation of orange precipitated indicated the presence of alkaloid (Abdurohman, 2015).

\section{ii. Tests for saponins}

The gel was diluted with distilled water and shaken ingraduated cylinder for 15 minutes. The formation of foam layer indicated the presence of saponins (Abdurohman, 2015).

\section{iii. Test for tannins}

The gel was dissolved in distilled water to which $2 \mathrm{~mL}$ of $5 \%$ ferric chloride solution was added.Formation of blue green indicated presence of tannins (Abdurohman, 2015).

\section{iv. Test for terpeniods}

The gel was in treated in chloroform with few drops of concentrated sulphuric acid, shaken properly and allowed to stand for some time; formation of yellow colored lower layer indicated the presence of terpenoids (Abdurohman, 2015).

v. Test for steroids

To $2 \mathrm{~mL}$ of gel, $5 \mathrm{~mL}$ of chloroform and $2 \mathrm{~mL}$ of aceticanhydride was added followed by concentrated $\mathrm{H}_{2} \mathrm{SO}_{4}$. Reddish brown coloration at interface indicated the presence of steroids (Abdurohman, 2015).

\section{vi. Test for flavonoids}

Few drops of ferric chloride solution were added to the gel. Formation of intense green color indicated thepresence of flavonoid (Abdurohman, 2015).

\section{vii. Test for cardiac glycosides}

To $2 \mathrm{~mL}$ of the gel, $3 \mathrm{~mL}$ of glacial acetic acid and 1 drop of $5 \%$ ferric chloride were added in a test tube. Carefully $0.5 \mathrm{~mL}$ of concentrated sulphuric acid was added by the side of the test tube. Formation of blue color in the acetic acid layer indicated the presence of cardiac glycosides (Abdurohman, 2015).

\section{viii. Test for phlobatannins}

The gel was boiled with $1 \%$ aqueous HCL. No deposition of red precipitate indicated the absence of phlobatannins (Ezeonu and Ejikeme, 2016).

Test bacterial isolates

Isolates of Staphylococcus aureus and Pseudomonas aeruginosa were collected from Microbiology laboratory of Barau Dikko Teaching Hospital, Kaduna. The isolates were collected on nutrient agar slants and 
UJMR, Volume 5 Number 2, December, 2020, pp 1 - $80 \quad$ ISSN: 2616 - 0668

transported to the laboratory, Department of Microbiology, Kaduna State University, Zaria for further assay.

Re-confirmation of Test bacterial Isolates

The isolates were re-confirmed based on their colonial morphology, Gram reaction and Biochemical reactions as described by Cheesbrough(2012).

Determination of Antibiotic Susceptibility Pattern of the Test Isolates

McFarland standard (0.5) was prepared by adding $0.05 \mathrm{~mL}$ of $1 \%$ Barium Chloride solution $\left(\mathrm{BaCl}_{2} .2 \mathrm{H}_{2} \mathrm{O}\right)$ to $99.4 \mathrm{~mL}$ of $1 \%(\mathrm{v} / \mathrm{v})$ sulphuric acid solution $\left(\mathrm{H}_{2} \mathrm{SO}_{4}\right)$ and mixed thoroughly. Inocula of the test isolates were standardized by emulsifying discrete colonies of the isolates into sterile normal saline and comparing the turbidity with that of 0.5 McFarland standard (Andrews, 2001).

The antibiotic susceptibility pattern of the isolates was determined by the Kirby Bauer disk diffusion method. Briefly, about $0.1 \mathrm{~mL}$ of each of the standardized bacterial suspension was inoculated evenly on to Mueller-Hinton agar plates with the aid of sterile swab sticks. The antibiotic discs were then placed on the surface of the media and allowed to diffuse for 10 minutes. Then the plates were incubated at $37^{\circ} \mathrm{C}$ for 18 hours. The diameters of the zones of inhibition were measured, recorded and interpreted as susceptible, intermediate or resistant using the Clinical Laboratory Standards Institute guideline (CLSI, 2018). Susceptibility of $S$. aureus to cefoxitin $(30 \mu \mathrm{g})$, chloramphenicol $(30 \mu \mathrm{g})$, gentamicin $(30 \mu \mathrm{g})$, ciprofloxacin $(5 \mu \mathrm{g})$, erythromycin $(15 \mu \mathrm{g})$, ceftaroline $(30 \mu \mathrm{g})$, sparfloxacin $(5 \mu \mathrm{g})$, clindamycin $(2 \mu \mathrm{g})$, nitrofurantoin $(300 \mu \mathrm{g})$ and trimethoprim/ sulfamethoxazole $(1.25 / 23.75 \mu \mathrm{g})$ as well as the susceptibility of $P$. aeruginosa to piperacillin $(100 \mu \mathrm{g})$, ticarcillinclavulanate $\quad(75 / 10 \mu g), \quad$ norfloxacin $(10 \mu \mathrm{g})$, ceftazidime $(30 \mu \mathrm{g}), \quad$ amikacin $(30 \mu \mathrm{g})$ chloramphenicol $(30 \mu \mathrm{g})$, gentamicin $(30 \mu \mathrm{g})$ and ciprofloxacin $(5 \mu \mathrm{g})$ were determined.

Antibacterial activity of Aloe vera gel against the test isolates

Antibacterial activity of Aloe vera gel against the test isolates was determined using agarwell diffusion method. About $0.1 \mathrm{~mL}$ of each of the standardized (0.5 McFarland) bacterial suspension were inoculated evenly on to
Mueller-Hinton agar plates using sterile swab sticks. With the aid of a sterilized cork borer, wells of $6 \mathrm{~mm}$ diameter were bored in the MHA. A $0.1 \mathrm{~mL}$ aliquot of $100 \mu \mathrm{g} / \mathrm{mL}, 50 \mu \mathrm{g} / \mathrm{mL}$, $25 \mu \mathrm{g} / \mathrm{mL}$ and $12.5 \mu \mathrm{g} / \mathrm{mL}$ concentrations of Aloe vera gel were added aseptically into the respective wells and the plates were then held for 1 hour at room temperature for the gel to diffuse before incubation for 24 hour at $37^{\circ} \mathrm{C}$. After incubation, the diameters of the zones of inhibition were measured to the nearest $\mathrm{mm}$ (Kingsbury and Wagner, 2013).

Determination of Minimum Inhibitory Concentration (MIC)

The lowest concentration of Aloe vera gel capable of preventing growth (Minimum Inhibitory Concentrations (MIC) was determined as follows; $2 \mathrm{~mL}$ of Muller-Hinton broth was transferred in to four sets of test tubes for each of the test isolates. Serial doubling dilution was carried out using $2 \mathrm{~mL}$ of the $200 \mu \mathrm{g} / \mathrm{mL}$ concentrations of the gel to achieve final concentrations of $100 \mu \mathrm{g} / \mathrm{mL}, \quad 50 \mu \mathrm{g} / \mathrm{mL}$, $25 \mu \mathrm{g} / \mathrm{mL}$ and $12.5 \mu \mathrm{g} / \mathrm{mL}$ respectively. One loopful each of the standardized inocula was inoculated into the tubes labelled appropriately and incubated at $37^{\circ} \mathrm{C}$ for 24 hours. The least concentration (highest dilution) that shows no sign of visible growth (turbidity) was recorded as the Minimum Inhibitory Concentrations (MIC) of the Aloe vera gel (Bandaru et al., 2017).

Determination of Minimum Bactericidal Concentration (MBC)

The Minimum Bactericidal Concentrations were determined by sub-culturing the contents of the Mueller-Hinton broth that showed no visible growth onto Mueller-Hinton agar plates by streaking using sterile wire loop, after which the plates were incubated at $37^{\circ} \mathrm{C}$ for 24 hours. The lowest concentration with no growth was considered as the Minimum Bactericidal Concentrations (MBCs) of the Aloe vera gel (Bandaru et al., 2017).

\section{RESULTS}

The phytochemical screening of Aloe vera gel for bioactive secondary metabolites revealed the presence of saponins, alkaloids, flavonoids, and terpenoids in the gel and the absence of steroids, phlobatannins, tannins and cardiac glycosides (Table 1). 
UJMR, Volume 5 Number 2, December, 2020, pp 1 - $80 \quad$ ISSN: 2616 - 0668

Table 1: Phytochemical constituents of Aloe vera Gel

\begin{tabular}{ll}
\hline Phytochemical constituents & Results \\
\hline Saponins & + \\
Flavonoids & + \\
Terpenoids & + \\
Alkaloids & + \\
Phlobatannins & - \\
Steroids & - \\
Tannins & - \\
Cardiac glycosides & - \\
\hline
\end{tabular}

Keys: + = present, - = absent

The study revealed that Staphylococcus aureus was resistant to 6 antibiotics of different classes namely: fluoroquinolone (ciprofloxacin), aminoglycoside (gentamicin), cephalosporin (cefaroline), folate pathway antagonist (trimethoprim-sulfamethoxazole), penicillin (cefoxitin) and macrolide (erythromycin) while Pseudomonas aeruginosa was resistant to 5 antibiotics of different classes namely: B-lactam (ticarcillin-clavulanate), fluoroquinolone (ciprofloxacin and norfloxacin), aminoglycoside (gentamicin) and cephalosporin (ceftazidime). The multiple antibiotic resistance (MAR) index of Staphylococcus aureus and Pseudomonas aeruginosa found to be was 0.60 and 0.63 (Table 2).

Table 2: Susceptibility patterns and Multiple Antibiotic Resistance (MAR) indices of the test isolates \begin{tabular}{lcccc}
\hline Isolates & $\begin{array}{c}\text { No. of antibiotic } \\
\text { tested }\end{array}$ & $\begin{array}{c}\text { Antibiotics } \\
\text { susceptible to }\end{array}$ & Antibiotics resisted & ${ }^{*} M A R$ \\
indices
\end{tabular}

\begin{tabular}{lclll}
\hline S.aureus & 10 & C, SPX, CC, F/M & CIP,CN,SXT,CPT,FOX,ERY & 0.60 \\
P.aeruginosa & 8 & PIP, AM, C & TIM,CIP,NOR,CN,CAZ & 0.63
\end{tabular}

Key: MAR=Multiple Antibiotic Resistance; CIP=ciprofloxacin; $\quad \mathrm{CN}=$ gentamicin; $\quad \mathrm{SXT}=$ trimethoprim/sulphamethoxazole; $\quad$ CPT=ceftaroline; $\quad F O X=$ cefoxitin; $\quad E R Y=e r y t h r o m y c i n ; T I M$ =ticarcillin-clavulanate; NOR=norfloxacin; CAZ=ceftazidime; $\mathrm{C}=$ hloramphenicol; SPX=sparfloxacin; $\mathrm{CC}=$ clindamycin; $\mathrm{F} / \mathrm{M}$ =nitrofurantoin; $\mathrm{PIP}=$ piperacillin; $\mathrm{AM}=$ amikacin

* MAR index was calculated as the ratio of the number of antibiotic resisted to the total number of antibiotic tested.

Table 3 illustrates the antibacterial activity of Aloe vera gel on the MDR isolates. It revealed that the gel exhibited its highest activity at the concentration of $100 \mu \mathrm{g} / \mathrm{mL}$ and produces zones of inhibition of $25 \pm 1.16 \mathrm{~mm}$ and $21 \pm 0.58 \mathrm{~mm}$ against MDR $S$. aureus and $P$. aeruginosa respectively. At the lowest concentration of $12.5 \mu \mathrm{g} / \mathrm{mL}$, the gel produces mean zones of inhibition of $09 \pm 0.44 \mathrm{~mm}$ and $07 \pm 0.88 \mathrm{~mm}$ against MDR S. aureus and $P$. aeruginosa respectively.

Table 3: Antibacterial activity of Aloe vera gel against the test isolates

Concentrations $(\mu \mathrm{g} / \mathrm{mL}) \quad$ Mean zones of inhibition $\pm \mathrm{SE}(\mathrm{mm})$

\begin{tabular}{lcc}
\cline { 2 - 3 } & S. aureus & P. aeruginosa \\
\hline 100 & $25 \pm 1.16$ & $21 \pm 0.58$ \\
50 & $20 \pm 0.58$ & $17 \pm 0.33$ \\
25 & $15 \pm 0.45$ & $12 \pm 0.17$ \\
12.5 & $09 \pm 0.44$ & $07 \pm 0.88$ \\
\hline
\end{tabular}

Table 4 revealed that the Minimum Inhibitory Concentration (MIC) of Aloe vera gel was recorded at $25 \mu \mathrm{g} / \mathrm{mL}$ and $50 \mu \mathrm{g} / \mathrm{mL}$ against MDR S.aureus and $P$. aeruginosa respectively. While the Minimum Bactericidal Concentration $(\mathrm{MBC})$ was recorded at $50 \mu \mathrm{g} / \mathrm{mL}$ and $100 \mu \mathrm{g} / \mathrm{mL}$ against MDR $S$. aureus and $P$. aeruginosa respectively.

Table 4: Minimum Inhibitory Concentration and Minimum Bactericidal Concentration of the Aloe vera gel against the test isolates

\begin{tabular}{lcc}
\hline Multidrug resistant isolates & Aloe vera \\
& MIC $(\mu \mathrm{g} / \mathrm{mL})$ & $\mathrm{MBC}(\mu \mathrm{g} / \mathrm{mL})$ \\
\hline Staphylococcus aureus & 25 & 50 \\
Pseudomonas aeruginosa & 50 & 100 \\
\hline
\end{tabular}




\section{DISCUSSION}

The findings of this study revealed the presence of presence of phytoconstituents such as saponins, alkaloids, terpenoids and flavonoids in the Aloe vera plant. The presence of these phytochemicals in Aloevera gel is in accordance with the report of Karpagam and Devaraj (2018). Saponins, alkaloids, terpenoids and flavonoids were previously reported to have broad spectrum of antimicrobial activity against bacteria, fungi and viruses (Abdurohman, 2015). Hence medicinal plants are regarded as synthetic laboratory where bioactive chemical compounds are produced (Jothi et al., 2014).

Susceptibility profile of the test isolates in this study shows that all the test isolates were resistant to more than 3 different classes of antimicrobial agents hence considered MDR isolates. So also the MAR indices of the isolates were higher than 0.2 suggesting that they originated from high risk sources where antibiotics are often used.The MAR index gives an insight on the number of isolates showing antibiotic resistance and the consequence risk zone in routine susceptibility testing (Olonitola et al., 2007).

Increase in the number of multi-drug resistant pathogenic microorganisms as well as undesirable side effects of some antimicrobials have led to the search for new effective antimicrobial drugs of plant origin. The findings of this study indicated that Aloe vera gel exhibited antibacterial activity against the test isolates at all the concentrations tested. This activity could be attributed to the presence of bioactive phytochemicals present in the $A$. vera gel. The study observed that the degree of inhibition varied directly with varying concentrations of the gel. Higher concentrations of the gel produce wider zones of inhibition against both the MDR S. aureus and MDR $P$. aeruginosa. These observations corroborate with those of Goudarzi et al. (2015).

Among the two isolates, higher antibacterial activity by the gel was observed against MDR S. aureus compared to MDR $P$. aeruginosa. This may be attributed to the higher MAR index of the MDR $P$. aeruginosa and the presence of outer membrane comprising of phospholipids

\section{REFERENCES}

Abdurohaman, M.Y.(2015). Phytochemical Extraction and Screening of Bio Active Compounds from Black Cumin (Nigella sativa)Seeds Extract. American Journal of Life Sciences, 3(5): 358-364.

Adnan, M.J., Al-Ahbabi, H.H., Alhussani, R. and Hamad, A.(2015). Study of the efficacy of Aloe vera extracts in treatment of

UMYU Journal of Microbiology Research and lipopolysaccharides covering the peptidoglycan of layer of $P$. aeruginosa (and other Gram negative bacteria) (Dahiya and Purkayastha, 2012). This outer membrane acts as barrier to entrance of most antimicrobials. This is in agreement with the report of Masoumian and Zandi (2017) and those of Antonisamy et al. (2012). However, it is in contradiction with the result of Goudarzi et al. (2015) who reported that none of the MDR isolates of Pseudomonas aeruginosa screened in their study weresensitive to $A$. vera gel at concentrations lower than $25 \mu \mathrm{g} / \mathrm{mL}$. Likewise, Anderl et al. (2010) reported that Aloe vera gel inhibited the growth of $S$. aureus isolated from wound infection but has no effect on $P$. aeruginosa isolates.

The MIC of Aloe vera gel was recorded at the concentration of $25 \mu \mathrm{g} / \mathrm{mL}$ against MDR Staphylococcus aureus and $50 \mu \mathrm{g} / \mathrm{mL}$ against MDR Pseudomonas aeruginosa while the MBC of Aloe vera gel was recorded at the concentration of $50 \mu \mathrm{g} / \mathrm{mL}$ against Staphylococcus aureus and $100 \mu \mathrm{g} / \mathrm{mL}$ against MDR Pseudomonas aeruginosa respectively. The higher MIC and MBC values for MDR Pseudomonas aeruginosa is an indication that the gel is less effective against the organism. This result is similar to the result of Takon et al. (2015). However, higher MIC values of $\leq 400 \mu \mathrm{g} / \mathrm{mL}$ was reported by Goudarzi et al. (2015) for most (89.4\%) of the MDR $P$. aeruginosa strains screened and $800 \mu \mathrm{g} / \mathrm{mL}$ MIC values for the remaining $10.6 \%$ of the isolates.

\section{CONCLUSION}

The study revealed that Aloe vera gel exhibited antibacterial activity against the test bacteria (MDR S. aureus and MDR Pseudomonas aeruginosa) with the gel having higher activity against MDR S. aureus (zone of inhibition at 100 $\mu \mathrm{g} / \mathrm{mL}=25 \pm 1.16 \mathrm{~mm}$ and $\mathrm{MIC}=25 \mu \mathrm{g} / \mathrm{mL}$ ) than MDR Pseudomonas aeruginosa (zone of inhibition at $100 \mu \mathrm{g} / \mathrm{mL}=21 \pm 0.58 \mathrm{~mm}$ and MIC $=50 \mu \mathrm{g} / \mathrm{mL}$ ). The study identifies that Aloe vera gel has shown great potential as an effective antibacterial agent for medicinal purposes and should be categorized among the agents considered in the search for novel antimicrobials.

non-infected wounds induced by sulferric acid and infected wounds with Staphylococcus aureus. International Journal of Advanced Research,3(1):593601.

Anderl, J.N., Franklin, M.J. and Stewart, P.S. (2010).Role of antibioticpenetration limitation in Klebsiella pneumoniae biofilm resistanceto ampicillin and www.ujmr.umyu.edu.ng 
UJMR, Volume 5 Number 2, December, 2020, pp 1 - $80 \quad$ ISSN: 2616 - 0668

ciprofloxacin.Antimicrobial Agents andChemotherapy, 44(7): 1818-1824.

Andrew, J.M. (2001). Determination of Minimum Inhibitory Concentrations. Journal of Antimicrobial Chemotherapy, 48(1):5-16

Antonisamy, J.M., Beaulah, N., Laju, R.S., Anupriya, G. (2012). Antibacterial and antifungal activity of Aloe vera gel extract. International Journal of Biomedical and Advance Research,1(3): 184-7.

Arunkumar, S. and Muthuselvam, M. (2009). Analysis of Phytochemical Constituents and Antimicrobial Activitiesof Aloe veraL. against Clinical Pathogens. World Journal of Agricultural Sciences, 5(5): 572-576.

Bandaru, N.R., Devi, D.L. and Srinivas, B. (2017). An evaluation Antimicrobial Activity of Aloebarbadensis Miller (Aloe vera) Gel Extract. Journal of Pharmaceutical and Biomedical Sciences. 21(21): 1-4.

Chambers, H.F. and DeLeo, F.R. (2009). Waves of Resistance: Staphylococcus aureusin the Antibiotic Era. Nature Review Microbiology, 7(9): 629-641.

Cheesbrough, M. (2012). District Laboratory Practice in Tropical Countries Part 2. Cambridge University Press, USA. 47-57.

Clinical and Laboratory Standards Institute (2018).Performance Standards for Antimicrobial Susceptibility Testing. 28th ed. CLSI supplement M100. Wayne, PA: Clinical and Laboratory Standards Institute; 2018.

Dahiya, P. and Purkayastha, S. (2012). Phytochemical Screening and Antimicrobial Activity of Some Medicinal Plants against Multi-Drug Resistant Bacteria from Clinical Isolates. Indian Journal of Pharmaceutical Sciences, 74(5): 443450.

Ezeonu, C.S. and Ejikeme, C.M. (2016). Qualitative and Quantitative Determination of Phytochemical Contents of Indigenous Nigerian Softwoods. New Journal of Science, 2016:1-9.

Foster, T.J. (2017). Antibiotic Resistance in Staphylococcus aureus. Current Status and Future Prospects. FEMS Microbiology Reviews, 41(3): 430-449.

Goudarzi, M.,Fazeli, M.,Azad, M.,Seyedjavadi, S.S. and Mousavi, R. (2015).Aloe veraGel: Effective Therapeutic Agent against Multidrug-Resistant Pseudomonas aeruginosalsolates Recovered from Burn Wound Infections.

UMYU Journal of Microbiology Research
Chemotherapy Research and Practice, 2015: 1-5

Hiramatsu, K., Baba, Katayama,Y., Matsuo, M. T. Sasaki, Y., Morimoto, $\mathrm{A}$ and Sekiguchi, T. (2014). Multi-drug resistant Staphylococcus aureusand future chemotherapy. Journal Infectious Chemotherapy, 20: 593-601.

Ingrida J., Lina, S. and Ruta, B.(2012). Ophthalmic Drug Delivery in GlaucomaA review. Pharmaceutics, 4(1):243-251.

Japoni, A., Farshad, S., and Alborzi, A. (2014). Pseudomonas aeruginosa: burn infection, treatment and antibacterial resistance. Iranian Red Crescent Medical journal11(2):244-253.

Jothi, K.R., Vijayalakshmi, K., Tamilarasi, L. and Ezhilarasi, B. (2014). Antibacterial activity of leaf extracts of Aloe vera, Ocimum sanctum and Sesbaniagrandiflora against the gram positive bacteria. International Journal of Biomedical and Pharmaceutical Sciences. 4(35): 60-63.

Karpagam, T. andDevaraj, R.A. (2011). Studies on the efficacy of Aloe vera on antimicrobial activity. International Journal of Research in Ayurveda and Pharmacy, 2(4).

Kingsbury, D.T. and Wagner, G.E. (2013).Microbiology $2^{\text {nd }}$ edition, $A$ Willey medical publication. The National Medical Series for Independent Study. California University USA.

Lowy, F.D. (2013). Antimicrobial resistance: the example of Staphylococcus aureus. Journal Clinical Investment, 111: 12651273.

Masoumian, M. and Zandi, M. (2017). Antimicrobial Activity of Some Medical Plant Extracts against Multidrug Resistant Bacteria. Zahedan Journal of Research in Medical Sciences,19(11): E10080

Olonitola, O.S., Olayinka, A.T., Inabo, H.I. andShaibu, A.M. (2007). Production of extendedspectrum beta - lactamases of urinary isolates of Escherichia coli and Klebsiella pneumoniae inAhmadu Bello University Teaching Hospital,Zaria, Nigeria. International Journal ofBiological and Chemical Sciences, 1(2):181-185.

Onemu, O.S. and Ophori, E.A. (2013). Prevalence of Multi-Drug Resistant Staphylococcus aureusin clinical specimens obtained from patients attending the University of Benin Teaching Hospital, Benin City, Nigeria. Journal of Natural Science, 3(5): 154159.

www.ujmr.umyu.edu.ng 
UJMR, Volume 5 Number 2, December, 2020, pp 1 - $80 \quad$ ISSN: 2616 - 0668

Radha, M. and Laxmipriya, N.P. (2015).

Evaluation of biological properties and clinical effectiveness of Aloe vera: A systematic review. Journal of Traditional and Complimentary Medicine, 5(1): 21-26.

Seyyed, A.H., Sayyed, A.H. and Saied, A. (2015). The Review on Properties on Properties of Aloe vera in Healing of the Cutaneous Wounds. BioMed Research International, 2015: 1-6.

Takon, I.A., Brooks, A.A. and Umah, C.C. (2015). Evaluation of the phytochemical properties and antimicrobial activity of Vernonia amygdalina against selected clinical isolates. Journal of Biopesticides and Environment,2(1-2): 7-11.

Yebpella, G.G., Hammuel, C., Adeyemi, H.M.M., Magomya, A.M., Agbaji, A.S. and Shallagwa, G. A. (2011). Phytochemical screening and a comparative study of antibacterial activity of Aloe vera green rind, gel and leaf pulp extracts. International Research Journal of Microbiology, 2(10): 382-386. 